\title{
Socioeconomic variation in incidence of primary and secondary major cardiovascular disease events: an Australian population-based prospective cohort study
}

\author{
Rosemary J. Korda ${ }^{1 *}$, Kay Soga ${ }^{1}$, Grace Joshy ${ }^{1}$, Bianca Calabria ${ }^{1,2}$, John Attia ${ }^{3}$, Deborah Wong ${ }^{1}$ and Emily Banks ${ }^{1,4}$
}

\begin{abstract}
Background: Cardiovascular disease (CVD) disproportionately affects disadvantaged people, but reliable quantitative evidence on socioeconomic variation in CVD incidence in Australia is lacking. This study aimed to quantify socioeconomic variation in rates of primary and secondary CVD events in mid-age and older Australians.

Methods: Baseline data (2006-2009) from the 45 and Up Study, an Australian cohort involving 267,153 men and women aged $\geq 45$, were linked to hospital and death data (to December 2013). Outcomes comprised first event death or hospital admission - for major CVD combined, as well as myocardial infarction and stroke, in those with and without prior CVD (secondary and primary events, respectively). Cox regression estimated hazard ratios (HRs) for each outcome in relation to education (and income and area-level disadvantage), separately by age group (45-64, 65-79, and $\geq 80$ years), adjusting for age and sex, and additional sociodemographic factors.

Results: There were 18,207 primary major CVD events over 1,144,845 years of follow-up (15.9/1000 person-years), and 20,048 secondary events over 260,357 years (77.0/1000 person-years). For both primary and secondary events, incidence increased with decreasing education, with the absolute difference between education groups largest for secondary events. Age-sex adjusted hazard ratios were highest in the 45-64 years group: for major CVDs, HR (no qualifications vs university degree) $=1.62$ (95\% Cl: 1.49-1.77) for primary events, and $H R=1.49(1.34-1.65)$ for secondary events; myocardial infarction $\mathrm{HR}=2.31$ (1.87-2.85) and $\mathrm{HR}=2.57(1.90-3.47)$ respectively; stroke $\mathrm{HR}=1.48$ $(1.16-1.87)$ and $H R=1.97(1.42-2.74)$ respectively. Similar but attenuated results were seen in older age groups, and with income. For area-level disadvantage, CVD gradients were weak and non-significant in older people (> 64 years).

Conclusions: Individual-level data are important for quantifying socioeconomic variation in CVD incidence, which is shown to be substantial among both those with and without prior CVD. Findings reinforce the opportunity for, and importance of, primary and secondary prevention and treatment in reducing socioeconomic variation in CVD and consequently the overall burden of CVD morbidity and mortality in Australia.
\end{abstract}

Keywords: Cardiovascular diseases, Incidence, Socioeconomic factors, Education, Disadvantage, Income, Health status disparities, Inequalities, Cohort, Australia

\footnotetext{
* Correspondence: rosemary.korda@anu.edu.au

${ }^{1}$ National Centre for Epidemiology and Population Health, Research School

of Population Health, Australian National University, Canberra, ACT, Australia

Full list of author information is available at the end of the article
} 


\section{Background}

Cardiovascular disease (CVD) is the leading cause of death and disability globally $[1,2]$. In Australia, although CVD mortality has decreased around $70 \%$ since the early 1980s [3], more people die from ischaemic heart disease than any other disease, followed closely by stroke [4], and CVD accounts for the greatest health care expenditure of any major disease group [5]. Around one in five Australians aged 45-74 are estimated to be at high absolute CVD risk - just over half of these have high primary risk, and the remainder have a history of prior CVD and hence are at high risk of a secondary event [6]. Despite this high background level of risk, a large proportion of CVD events can be prevented using populationand individual-level interventions and there remains substantial potential for further reductions in CVD incidence and mortality.

The potential for CVD prevention is likely to be greatest in the most disadvantaged groups within the population, given that the CVD burden is highest in these groups [7]. Nevertheless, there is a lack of reliable quantitative evidence on socioeconomic variation in the incidence of CVD in Australia. In this country, aggregate CVD hospital admissions and mortality data are typically used to report on variation in CVD, with inequalities described in relation to area-level disadvantage [7-10]. However, these data do not allow estimation of CVD incidence, and they will necessarily underestimate socioeconomic variation in CVD events. In contrast, population-based prospective cohort studies can quantify variation in incidence by incorporating individual-level socioeconomic factors and tracking CVD events (both fatal and non-fatal) in individuals. Studies of this type undertaken in highincome countries other than Australia generally report higher incidence of primary (incident) CVD, usually myocardial infraction or stroke, among people of lower socioeconomic position (SEP) [10-29]. However, while the relationships between SEP and CVD outcomes are broadly similar across industrialised countries and may be similar in Australia, local contemporary data are important for quantifying the magnitude of the problem. This evidence is critical to prioritising and targeting interventions, and for evaluating progress. We could identify only two population-based prospective studies using Australian data. One study of mid-age women found decreasing incidence of self-reported stroke with increasing education, and a pooled cohort study using linked data (Australia and New Zealand (NZ) combined), reported increasing event rates (primary and secondary combined) with decreasing education for total CVD and coronary heart disease, but not for stroke [30].

World-wide, there is scant evidence on socioeconomic variation in incidence of secondary CVD events (i.e. in those with existing CVD or history of a prior event)
[31]. We could not identify any Australian studies on this. The distinction between primary (incident) and secondary events is important given the much larger absolute risk of a CVD event in those with prior CVD and hence potentially greater absolute benefits from intervention. In addition, approaches to prevention and treatment, and methodological implications, for these outcome types differ. Quantification of such variation necessarily requires individual-level longitudinal data on both non-fatal and fatal specific CVD endpoints; information on prior CVD history; and individual-level rather than area-based measures of SEP, with studies based on the latter likely to underestimate variation [32].

The aim of this study was to use large-scale individuallevel linked survey and administrative data to quantify individual-level socioeconomic variation in rates of primary and secondary CVD events, in a population-based cohort of mid-age and older Australians.

\section{Methods \\ Data}

We used data from the Sax Institute's 45 and Up Study, an Australian cohort involving 267,153 men and women aged 45 and over from New South Wales (NSW), Australia. Participants in the Study were randomly sampled from the database of Australia's universal health insurance provider, Medicare Australia, with over-sampling by a factor of two, of individuals aged 80 years and over and people resident in rural areas. Around 10\% of the entire NSW population aged 45 and over were included in the sample. Participants joined the Study by completing a baseline questionnaire (between Jan 2006 and April 2009) and giving signed consent for follow-up and linkage of their information to a range of health databases. The Study is described in detail elsewhere [33], and questionnaires can be viewed online [34].

Baseline survey data from the participants were linked to hospital data from the NSW Admitted Patient Data Collection (APDC, 1 July 2000 to 31 December 2013), data on date of death from the NSW Registry of Births, Deaths and Marriages (1 January 2006 to 31 December 2013), and data on causes of death from the Cause of Death Unit Record File (1 January 2006 to 31 December 2013). The APDC includes records of all hospitalisations in NSW, dates of admission and discharge and reasons for admission. Each record in APDC contains up to 51 diagnosis codes using the International Statistical Classification of Diseases and Related Health Problems, Tenth Revision, Australian Modification (ICD-10-AM) codes and up to 50 procedure codes using the Australian Classification of Health Interventions (ACHI) codes. The Cause of Death Unit Record File includes primary causes of death and up to 20 additional causes using ICD-10-AM. Data were linked probabilistically 
by the Centre for Health Record linkage using personal information (including full name, date of birth, sex and address). Over the relatively short follow-up period, a small but unknown number of participants are likely to have moved out of NSW. Although hospitalisations occurring in neighbouring states would not be captured, these are estimated to make up fewer than $2 \%$ of admissions in NSW residents. Hence, follow-up for hospitalisations is considered to be $\sim 98 \%$ complete among those continuing to reside in NSW. Quality assurance data on the data linkage show false positive and negative rates of $<0.5 \%$ and $<0.1 \%$, respectively.

\section{Outcomes}

The main outcome was a major CVD event: a composite endpoint of fatal or non-fatal major CVD, ascertained through first hospital admission for major CVD, or death due to CVD, following recruitment into the study. We defined major CVD as a sub-group of circulatory diseases that have a significant atherosclerotic or arteriovenous thromboembolic component, based on a combination of diagnosis codes from ICD-10-AM and CVD-related intervention procedure codes from the $5^{\text {th }}$ to $7^{\text {th }}$ editions of ACHI [35]. In addition, we separately examined two common CVD subtypes: myocardial infarction (ICD-10-AM codes: I21 and I22) and stroke (intracerebral haemorrhage, infarction or transient ischaemic attack, ICD-10-AM codes: I61, I63, I64, and G45). In a supplementary analysis we also report results for ischaemic heart disease combined (ICD-10-AM codes: I20-I25) for comparison with other published results. We ascertained outcomes using the primary diagnosis code field (and procedure fields) of the APDC, and the primary cause of death code field of the Cause of Death Unit Record File.

In order to distinguish primary from secondary CVD events, we analysed outcomes separately in those with and without prior history of CVD. Prior CVD was defined as self-reported heart disease, stroke, or blood clot (thrombosis) on the baseline questionnaire, and/or hospital admission for major CVD ascertained from the 51 diagnosis code fields and the 50 procedure code fields of APDC in the 6 years prior to entering the study.

For each analysis, participants contributed person-years from recruitment date to the outcome of interest (first major CVD/myocardial infarction/stroke/ischaemic heart disease hospital admission or death), death from any cause, or end of follow up (31 December 2013), whichever was the earliest.

\section{Main exposure: socioeconomic position}

Socioeconomic position was based on education attainment, as well as two supplementary socioeconomic exposures for comparison-annual household income and area-level disadvantage. Education attainment was used as the primary socioeconomic variable as it is an individual as opposed to area-based measure. In addition, unlike household income, education attainment is a stable indicator of SEP from relatively early in the life course, is unlikely to be subject to reverse causality (i.e. CVD outcomes impacting on SEP), and is considered to be reliably reported with little missing data.

Education attainment was self-reported in defined categories, which were grouped for the analysis: No qualifications ("no school certificate or other qualifications"); certificate/diploma/trade ("school or intermediate certificate or equivalent," "higher school or leaving certificate or equivalent," "trade/apprenticeship, e.g. hairdresser, chef," "certificate/diploma, e.g., child care, technician"); and university degree ("university degree or higher"). Annual household income (from all sources, before tax) was self-reported in six defined brackets, which were grouped for analysis: $<\$ 20,000, \$ 20,000-<\$ 40,000, \$ 40,000-<\$ 70,000, \geq \$ 70,000$ and missing. Area-level disadvantage was based on the Australian Bureau of Statistics Index of Relative Socioeconomic Disadvantage (IRSD), a measure derived from Census data which summarises socioeconomic disadvantage in a particular area. [36] We categorised the IRSD into population-based quintiles using 2006 Australian Census data, and assigned it to individuals using their postcode of residence.

\section{Analysis}

All analyses were conducted separately in those with and without prior CVD. First, we calculated rates of major CVD in relation to education, separately in males and females. Rates were standardised by age to the 2006 NSW population, in 5year age groups, using the direct method [37], and rates differences (RD) and rate ratios (RR) were calculated, comparing rates in the lowest education group to those in the highest.

Second, Cox regression was used to estimate hazard ratios (HRs) for each outcome (major CVD/myocardial infarction/stroke/ischaemic heart disease hospital admission or death) in relation to education, with age as the underlying time variable, as a measure of relative differences in outcomes according to SEP. Analyses were performed separately for three age groups (45-64, 65-79, and $\geq 80$ years). Model 1 was adjusted for age (as the underlying time variable) and sex. Model 2 was adjusted for age, sex, region of birth (born in Australia/NZ and born in other countries) and region of residence (major cities, inner regional, and outer regional/remote/very remote). Model 3 was adjusted for the same factors as Model 2 and additionally adjusted for private health insurance (hospital/Department of Veterans Affairs concession card and no private health insurance). Participants with missing values for the main SEP measure were dropped from that analysis. Missing values for covariates were included in the models as separate categories. In supplementary analyses, we calculated age-adjusted rates 
and estimated HRs for major CVD in relation to income and area-based disadvantage (Model 1 only).

Two sets of sensitivity analyses were performed. In the first, we re-defined prior history of CVD to exclude selfreported blood clot (thrombosis) and re-ran the analyses for all outcomes; in the second analyses, we excluded transient ischaemic attack from the definition of stroke.

The proportional hazards assumption was verified using tests based on the Schoenfeld residuals for each model (significance level of 0.0001 was used due to the large sample size). Stratified forms of the models were used where covariates showed non-proportionality of hazards. Tests for linear trend were also performed for each model. All analyses were performed using Stata version 12.

\section{Results}

After excluding individuals with linkage errors $(n=196)$ and those aged less than 45 years at baseline $(n=8)$, the sample included 266,684 participants. Mean age was 63 years (Standard deviation $(\mathrm{SD})=11$ ), with $61 \%$ aged 45-64 years, 28\% aged 65-79 years, and 10\% aged $80+$ years. Just over half of all participants (54\%) were female. Of the total sample, $12 \%$ had no qualifications, $65 \%$ a certificate, diploma or trade and $23 \%$ a university degree, with education levels higher in the younger than older cohorts. One in five people (22\%) reported a history of prior CVD, ranging from $12 \%$ in those aged $45-64$, to $51 \%$ in those aged 80 or older. Further sample characteristics are shown in Table 1.

There were a total of 38,255 major CVD events over 1,405,202 years of follow-up (median follow-up = 5.37 years), a rate of 27.2 per 1000 person-years. There were 18,207 primary major CVD events (i.e. events in people with no prior CVD) over 1,144,845 years, a rate of 15.9 per 1000 person-years, and 20,048 secondary events (i.e. events in people with prior CVD) over 260,357 years, a rate of 77.0 per 1000 person-years.

For both primary and secondary major CVD events, agestandardised rates decreased with increasing education, among both males and females (Fig. 1). For primary events, age-standardised rates for males ranged from 18.6 per 1000 person years among those with a university degree to 22.7 per 1000 person years among those with no school qualifications ( $R D=4.07 ; \mathrm{RR}=1.22$ ), with the corresponding rates in females being 10.4 and 15.3 per 1000 person years $(R D=4.86 ; R R=1.47)$. Rate differences were notably higher for secondary events, with age-standardised rates for males ranging from 59.4 per 1000 person years among those with a university degree to 86.4 per 1000 person years among those with no qualifications $(\mathrm{RD}=27.0$; $R \mathrm{R}=1.45$ ); the corresponding rates in females were 36.0 and 50.9 per 1000 person years $(\mathrm{RD}=14.9 ; \mathrm{RR}=1.41)$.
After adjusting for age and sex (Model 1), HRs increased with increasing education in each age group for both primary and secondary events, as indicated by the tests for trend (Table 2). In the 45-64 years age group, rates were around $50-60 \%$ higher among those with no qualifications than among those with a university degree, for both primary $(\mathrm{HR}=1.62$, 95\% CI: $1.49-1.77)$ and secondary $(\mathrm{HR}=1.49$; 95\% CI: $1.34-1.65)$ major CVD events. Additional adjustment for region of birth and region of residence (Model 2) and also private health insurance (Model 3) made little difference to the HR estimates (Additional file 1: Table S1). Similar but attenuated results were seen in the older age groups (65-79 and $\geq 80$ years) (Table 2).

Analyses conducted for myocardial infarction only, which accounted for $17 \%$ of primary and $16 \%$ of secondary major CVD events, obtained similar patterns to analyses for total major CVD events but HRs were substantially higher, in all age groups (Table 2). In the 45-64 years age group, myocardial infarction rates were around two and half times higher among those with no qualifications than among those with a university degree for both primary $(\mathrm{HR}=2.31,95 \%$ CI: $1.87-2.85)$ and secondary $(\mathrm{HR}=2.57 ; 95 \% \mathrm{CI}$ : 1.90-3.47) events. Even in the older participants, rates were around $40 \%$ higher in the least compared to the most educated group (primary event HRs: 1.37, 95\% CI: $1.05-1.80$; and secondary events: $H R=1.38$, 95\% CI: 1.13-1.68). Analyses conducted for ischaemic heart disease events combined, which accounted for nearly half of all primary (44\%) and secondary (47\%) major CVD events, obtained similar results to analyses for total major CVD events (Additional file 2: Table S2).

Patterns for stroke, which accounted for $17 \%$ of both primary and secondary major CVD events, were also similar to those for all major CVD although trends were not significant for primary events among the two older age groups (65-79 and $\geq 80$ years, Table 2). Hazard ratios were again highest in the $45-$ 64 year age group, with a $50 \%$ higher risk of stroke among those with no qualifications compared to those with a university degree, for primary events $(\mathrm{HR}=$ $1.48,95 \%$ CI: $1.16-1.87)$ and a nearly two-fold $(100 \%)$ greater risk for secondary events $(H R=1.97$, 95\% CI: $1.42-2.74)$.

Hazard ratios for the two sets of sensitivity analyses one excluding self-reported thrombosis from the definition of prior CVD (resulting in 928 events (2.5\%) being re-classified as primary rather than secondary), and the other excluding transient ischaemic attack from the definition of the stroke outcome (resulting in 2289 (36\%) fewer events) - did not differ materially from those for the main analyses. 
Table 1 Characteristics of study participants at baseline

\begin{tabular}{|c|c|c|c|c|c|c|c|c|}
\hline Age group & $45-64$ & & $65-79$ & & $\geq 80$ & & All age groups & \\
\hline \multirow[t]{2}{*}{ Mean age \pm SD } & $55 \pm 5.41$ & & $71 \pm 4.26$ & & $84 \pm 3.54$ & & $63 \pm 11.17$ & \\
\hline & Number & $\%$ & Number & $\%$ & Number & $\%$ & Number & $\%$ \\
\hline All participants & 163660 & 100 & 75940 & 100 & 27084 & 100 & 266684 & 100 \\
\hline \multicolumn{9}{|l|}{ Sex } \\
\hline Male & 70502 & 43 & 39300 & 52 & 13893 & 51 & 123695 & 46 \\
\hline Female & 93158 & 57 & 36640 & 48 & 13191 & 49 & 142989 & 54 \\
\hline \multicolumn{9}{|l|}{ Education } \\
\hline No qualifications & 13690 & 8 & 12320 & 17 & 5225 & 20 & 31235 & 12 \\
\hline Certificate/diploma/trade & 102243 & 63 & 50004 & 67 & 17231 & 66 & 169478 & 65 \\
\hline University degree & 46083 & 28 & 11966 & 16 & 3465 & 13 & 61514 & 23 \\
\hline \multicolumn{9}{|l|}{ Annual household income } \\
\hline$<\$ 20,000$ & 18853 & 14 & 23541 & 42 & 10027 & 55 & 52421 & 25 \\
\hline$\$ 20,000-<\$ 40,000$ & 23904 & 18 & 17743 & 31 & 4988 & 27 & 46635 & 22 \\
\hline$\$ 40,000-<\$ 70,000$ & 35401 & 26 & 9567 & 17 & 2128 & 12 & 47096 & 23 \\
\hline$\geq \$ 70,000$ & 55905 & 42 & 5676 & 10 & 1195 & 7 & 62776 & 30 \\
\hline \multicolumn{9}{|l|}{ IRSD socioeconomic quintile } \\
\hline 1 (most disadvantaged) & 30095 & 18 & 16234 & 21 & 4629 & 17 & 50958 & 19 \\
\hline 2 & 39896 & 24 & 20384 & 27 & 5975 & 22 & 66255 & 25 \\
\hline 3 & 33061 & 20 & 14763 & 19 & 4978 & 18 & 52802 & 20 \\
\hline 4 & 30579 & 19 & 12664 & 17 & 5155 & 19 & 48398 & 18 \\
\hline 5 (least disadvantaged) & 29866 & 18 & 11858 & 16 & 6338 & 23 & 48062 & 18 \\
\hline \multicolumn{9}{|l|}{ Region of birth } \\
\hline Australia/NZ & 127970 & 79 & 57703 & 77 & 19191 & 72 & 204864 & 77 \\
\hline Other & 34720 & 21 & 17343 & 23 & 7417 & 28 & 59480 & 23 \\
\hline \multicolumn{9}{|l|}{ Region of residence } \\
\hline Major cities & 72554 & 44 & 30653 & 40 & 16867 & 62 & 120074 & 45 \\
\hline Inner regional & 57828 & 35 & 29087 & 38 & 6793 & 25 & 93708 & 35 \\
\hline Outer regional/remote/very remote & 33126 & 20 & 16166 & 21 & 3415 & 13 & 52707 & 20 \\
\hline \multicolumn{9}{|l|}{ Private health insurance } \\
\hline Yes (hospital/DVA) & 111826 & 68 & 45687 & 60 & 16305 & 60 & 173818 & 65 \\
\hline No & 51833 & 32 & 30247 & 40 & 10777 & 40 & 92857 & 35 \\
\hline \multicolumn{9}{|l|}{ Prior major CVD } \\
\hline Yes & 19577 & 12 & 24953 & 33 & 13775 & 51 & 58305 & 22 \\
\hline No & 144083 & 88 & 50987 & 67 & 13309 & 49 & 208379 & 78 \\
\hline
\end{tabular}

\% show characteristics within a given age group. Denominators of the percentages do not include missing cases. Number of missing cases: education $=4,457$ (1.7\%); annual household income $=57,756(21.7 \%)$; IRSD socioeconomic quintile $=209(0.1 \%)$; region of birth $=2,340(0.9 \%)$; region of residence $=195(0.1 \%)$; private health insurance $=9(<0.1 \%)$

Similar relationships between SEP and major CVD incidence were seen when rates were modelled according to annual household income, although SEP trends were not significant in the older age group ( $\geq 80$ years); when arealevel disadvantage was the measure of SEP, gradients were weak (45-64 years age group) or non-significant (65-79 and $\geq 80$ years age groups) (Additional file 3: Figure S1 and Additional file 4: Table S3).

\section{Discussion}

Large-scale, individual-level prospective data on mid-age and older Australians revealed substantial socioeconomic variation in the incidence of both primary and secondary CVD events, with rates higher among disadvantaged people. For both those with and without prior CVD in age group 45-64, major CVD incidence rates were around 50-75\% higher, myocardial incidence 


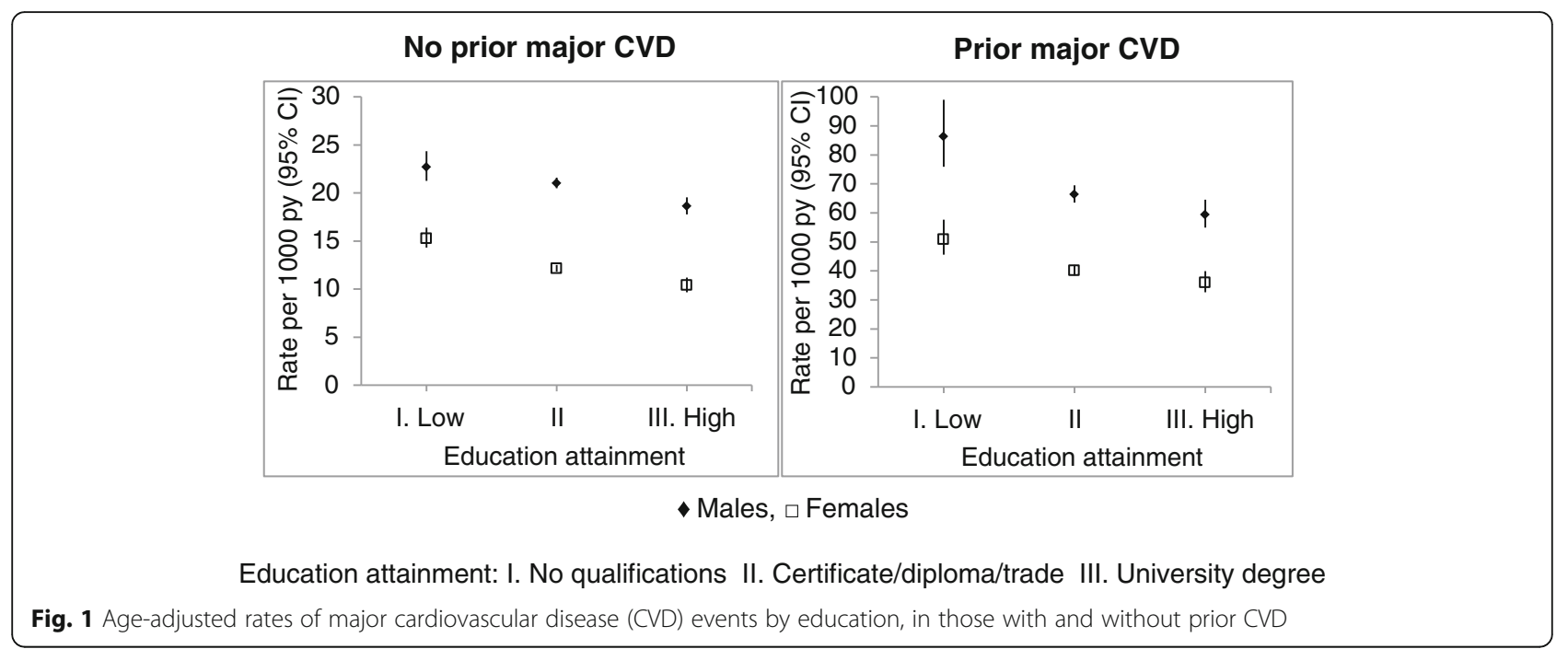

around 250\% higher and stroke incidence rates around $50-100 \%$ higher, among those of low SEP (no educational qualifications) compared to those of high SEP (university degree). Similar but attenuated relative inequalities were seen in the two older age groups (65-79 and $\geq 80$ ); however, when using area-level as a proxy for individual SEP there was no significant socioeconomic variation in these older age groups. The absolute difference in rates between socioeconomic groups was considerably larger for secondary than primary events, with rate differences in overall CVD incidence between the highest and lowest educational groups for secondary major CVD events six-fold higher than for primary major CVD events in males, three-fold higher in females.

While it is difficult to directly compare the magnitude of socioeconomic variation in CVD across studies, that incidence of primary CVD events increased with increasing disadvantage is consistent with international evidence. With few exceptions, (e.g., [30]), prospective cohort studies in high-income countries report higher incidence of ischaemic heart disease and stroke among those of lower SEP [10, 11, 13-26, 28, 29, 31, 38-43]. They are also consistent with a recent large prospective United Kingdom (UK) study, where relative rates of atherosclerotic CVD subtypes, including unstable angina, ischaemic stroke, intracerebral haemorrhage, myocardial infarction, heart failure and peripheral arterial disease, varied inversely with area-level deprivation [43]. Our findings on socioeconomic variation in stroke incidence are also consistent with an Australian prospective study on incident stroke in mid-age Australian women (1996-2008) using self-reported data [44], and with a study based on aggregated stroke registry and census data (1995-2003) [45]. However they differ from a pooled cohort study using Australian/NZ data, which found increasing event rates (primary and secondary combined) with decreasing education for all CVD and coronary heart disease, but not for stroke [30]. These differing findings may not only reflect differences within the Australian and NZ populations but also different methods (definition of endpoints, consideration of prior CVD history), and given the attenuation of risks in older age groups, different age structures across the studies.

To our knowledge, this is the first Australian study to have quantified variation in incidence of secondary CVD events and there are few international studies with which to compare our findings. The magnitude of income-related relative inequalities in rates of incident myocardial infarction reported in a Finnish populationbased study were slightly lower than those for incident and subsequent myocardial infarctions combined [39]. Limited evidence also comes from prospective studies on stroke recurrence in several European studies. In a Swedish prospective study (1990-2001), while incident stroke was associated with lower income and occupation in both men and women, recurrent stroke was inversely associated with income only in women [40]; in an Italian study (2001-2004), among those who had survived a first stroke, low SEP (measured at the small area level) was associated with a subsequent admission for stroke (in men) and cardiovascular disease (in women) [46]; a UK population-based study (1995-2004) reported no difference in stroke recurrence between manual and non-manual occupations [47]. Despite the lack of previous evidence for comparison, the higher absolute inequalities for secondary compared to primary CVD events found in this study is consistent with a priori expectations, given that the absolute risk of a CVD event is higher amongst those who have had a prior CVD event than among those who have not. 
Table 2 Crude rates of major cardiovascular disease (CVD), myocardial infarction and stroke events and adjusted hazard ratios (HR), by education, in those with and without prior CVD

\begin{tabular}{|c|c|c|c|c|c|c|}
\hline & \multicolumn{3}{|c|}{ No prior major CVD } & \multicolumn{3}{|c|}{ Prior major CVD } \\
\hline & Events/py ${ }^{a}$ & Crude rates $^{\mathrm{b}}$ & Adjusted $\mathrm{HR}^{\mathrm{C}}(95 \% \mathrm{Cl})$ & Events/py ${ }^{a}$ & Crude rates $^{b}$ & Adjusted HR $(95 \% \mathrm{Cl})$ \\
\hline \multicolumn{7}{|l|}{ Major CVD } \\
\hline \multicolumn{7}{|l|}{ 45-64 years } \\
\hline No qualifications & $776 / 62450$ & 12.43 & $1.62(1.49-1.77)$ & $644 / 12269$ & 52.49 & $1.49(1.34-1.65)$ \\
\hline Cert./diploma/trade & $4663 / 505833$ & 9.22 & $1.27(1.20-1.35)$ & $2630 / 63613$ & 41.34 & $1.17(1.08-1.27)$ \\
\hline University degree & $1669 / 236864$ & 7.05 & 1.00 & $795 / 22087$ & 35.99 & 1.00 \\
\hline$p$ (test for trend) & & & $<0.0001$ & & & $<0.0001$ \\
\hline \multicolumn{7}{|l|}{$65-79$ years } \\
\hline No qualifications & $1171 / 41,502$ & 28.22 & $1.13(1.04-1.23)$ & $1672 / 19615$ & 85.24 & $1.24(1.15-1.34)$ \\
\hline Cert./diploma/trade & $4830 / 178362$ & 27.08 & $1.11(1.04-1.18)$ & $5929 / 72579$ & 81.69 & $1.17(1.10-1.24)$ \\
\hline University degree & $1123 / 44967$ & 24.97 & 1.00 & $1147 / 15962$ & 71.86 & 1.00 \\
\hline$p$ (test for trend) & & & 0.0032 & & & $<0.0001$ \\
\hline \multicolumn{7}{|l|}{$\geq 80$ years } \\
\hline No qualifications & $744 / 11810$ & 63.00 & $1.11(0.99-1.25)$ & 1338/9213 & 145.23 & $1.15(1.06-1.26)$ \\
\hline Cert./diploma/trade & 2300/39396 & 58.38 & $0.99(0.90-1.10)$ & $4400 / 32563$ & 135.12 & $1.07(0.99-1.15)$ \\
\hline University degree & $483 / 7912$ & 61.05 & 1.00 & $871 / 6666$ & 130.67 & 1.00 \\
\hline$p$ (test for trend) & & & 0.0402 & & & 0.0009 \\
\hline \multicolumn{7}{|l|}{ Myocardial infarction } \\
\hline \multicolumn{7}{|l|}{$45-64$ years } \\
\hline No qualifications & $142 / 64112$ & 2.21 & $2.31(1.87-2.85)$ & 103/13973 & 7.37 & $2.57(1.9-3.47)$ \\
\hline Cert/diploma/trade & $813 / 516122$ & 1.58 & $1.68(1.45-1.95)$ & $351 / 70833$ & 4.96 & $1.69(1.31-2.17)$ \\
\hline University degree & $227 / 240648$ & 0.94 & 1.00 & $74 / 24280$ & 3.05 & 1.00 \\
\hline$p$ (test for trend) & & & $<.0001$ & & & $<.0001$ \\
\hline \multicolumn{7}{|l|}{$65-79$ years } \\
\hline No qualifications & $201 / 44059$ & 4.56 & $1.62(1.3-2.01)$ & $285 / 23645$ & 12.05 & $1.79(1.46-2.20)$ \\
\hline Cert./diploma/trade & 756/188974 & 4.00 & $1.44(1.2-1.72)$ & $824 / 87810$ & 9.38 & $1.36(1.14-1.63)$ \\
\hline University degree & $138 / 47538$ & 2.90 & 1.00 & 137/19134 & 7.16 & 1.00 \\
\hline$p$ (test for trend) & & & $<.0001$ & & & $<.0001$ \\
\hline \multicolumn{7}{|l|}{$\geq 80$ years } \\
\hline No qualifications & 157/13017 & 12.06 & $1.37(1.05-1.80)$ & 274/11678 & 23.46 & $1.38(1.13-1.68)$ \\
\hline Cert./diploma/trade & $470 / 43431$ & 10.82 & $1.18(0.93-1.49)$ & $806 / 40975$ & 19.67 & $1.14(0.95-1.35)$ \\
\hline University degree & $85 / 8812$ & 9.65 & 1.00 & $154 / 8424$ & 18.28 & 1.00 \\
\hline$p$ (test for trend) & & & 0.0164 & & & 0.0010 \\
\hline \multicolumn{7}{|l|}{ Stroke } \\
\hline \multicolumn{7}{|l|}{$45-64$ years } \\
\hline No qualifications & $97 / 64333$ & 1.51 & $1.48(1.16-1.87)$ & 78/14046 & 5.55 & $1.97(1.42-2.74)$ \\
\hline Cert./diploma/trade & $601 / 516740$ & 1.16 & $1.21(1.03-1.41)$ & 275/70991 & 3.87 & $1.38(1.06-1.81)$ \\
\hline University degree & $224 / 240687$ & 0.93 & 1.00 & $67 / 24376$ & 2.75 & 1.00 \\
\hline$p$ (test for trend) & & & 0.0009 & & & $<.0001$ \\
\hline \multicolumn{7}{|l|}{$65-79$ years } \\
\hline No qualifications & $203 / 44046$ & 4.61 & $1.08(0.88-1.31)$ & 290/23614 & 12.28 & $1.29(1.07-1.55)$ \\
\hline Cert./diploma/trade & $846 / 188872$ & 4.48 & $1.09(0.93-1.28)$ & $940 / 87274$ & 10.77 & $1.13(0.96-1.32)$ \\
\hline
\end{tabular}


Table 2 Crude rates of major cardiovascular disease (CVD), myocardial infarction and stroke events and adjusted hazard ratios (HR), by education, in those with and without prior CVD (Continued)

\begin{tabular}{lllllll}
\hline $\begin{array}{l}\text { University degree } \\
p \text { (test for trend) }\end{array}$ & $191 / 47433$ & 4.03 & 1.00 & $182 / 18963$ & 9.6 & 1.00 \\
$\geq 80$ years & & & 0.4795 & & 0.0067 \\
No qualifications & $189 / 12917$ & 14.63 & $1.08(0.85-1.36)$ & $320 / 11548$ & 27.71 & $1.44(1.18-1.76)$ \\
Cert./diploma/trade & $604 / 43098$ & 14.01 & $1.02(0.84-1.24)$ & $991 / 40330$ & 24.57 & $1.32(1.11-1.57)$ \\
University degree & $120 / 8728$ & 13.75 & 1.00 & $151 / 8347$ & 18.09 & 1.00 \\
$p$ (test for trend) & & & 0.4983 & & & 0.0006 \\
\hline
\end{tabular}

${ }^{\mathrm{a}}$ Events $=$ incident hospital admission or death and py $=$ person years of follow-up. ${ }^{\mathrm{b}}$ Rates are per 1000 person-years. ${ }^{\mathrm{C}} \mathrm{HRs}$ adjusted for age and sex

That relative inequalities were greater in mid-age (45-64 years) than older people-across the various outcomes and the different measures of SEP-is in line with previous international evidence $[15,16,23,25,39,48]$. This attenuating RR will occur wherever absolute risk increases with increasing exposure (as is usually the case with age) and RDs remain constant (and in some cases even if RDs rise). This age attenuation in RRs may also reflect the 'survivor effect' (whereby the negative effect of low SEP on health means those remaining in the cohort are not a random sample of the population but rather reflect those who are more likely to have survived the effect of low SEP on premature mortality); change in risk actors with age; and/or that the selected SEP variables-education, household income and area-level disadvantage-are less accurate measures of SEP in older than younger people. That socioeconomic variation was not apparent in the two older age groups when area-level was used as the SEP measure is consistent with the expectation that when such measures are used as a proxy for individual SEP there is likely to be considerable misclassification of individuals, and hence, underestimation of socioeconomic variation in the outcome. As has been noted previously, this underestimation is important to take into account when making decisions based on area-level inequality estimates [32].

The strengths of our prospective cohort study include: its large sample size, enabling examination of outcomes separately in relation to CVD subtypes and by age group; independent ascertainment of outcomes, including both fatal and non-fatal endpoints, with virtually complete follow-up through linkage to administrative hospital and death records; and availability of individual-level sociodemographic factors and measures of SEP. However, there are several limitations that should be borne in mind when interpreting the results. First, administrative hospital and death data may not capture all major CVD events, although they are likely to capture the vast majority. Second, data on education and income were selfreported, which means possible misclassification of SEP, although this is likely to be non-differential and, if anything, bias results towards the null; also we did not capture changes over time in SEP. Third, while the 45 and Up cohort are broadly representative of the Australian population in this age group, they are likely to be healthier and have lower hospitalisation and mortality rates than the general population in this age group. Further, consistent with many population-based cohort studies, the design aimed to maximise heterogeneity of exposure and to retain participants rather than provide a sample that is necessarily representative of the general population, and thus caution should be used when interpreting and generalising absolute incidence estimates. However, representativeness is not necessary for reliable estimates of relative rates based on internal comparisons within study populations $[49,50]$, and the relative inequality estimates, as measured in this study, are assumed to be valid and broadly generalizable, albeit potentially biased toward the null given the likelihood of some non-differential misclassification of SEP and outcome variables. Finally, the study did not set out to attribute causality, hence the minimal adjustment for other explanatory variables in the models. Consequently, some caution should be applied when attributing causality. This caution particularly applies to the findings on variation in secondary events by income due to the possibility of reverse causality (i.e. that a previous CVD event will lead to a loss of income), especially in the 45-64 age group who are of working-age.

\section{Implications and conclusions}

Individual-level longitudinal data on both fatal and non-fatal CVD outcomes are important for quantifying socioeconomic variation in CVD incidence. Based on individual-level SEP measures, socioeconomic variation in CVD incidence is shown to be substantial, not just for primary events, but also for secondary events. Given CVD is largely preventable and socioeconomic variation technically avoidable, our findings suggest large potential for reductions in CVD burden.

While our study did not examine the reasons underlying socioeconomic variation in incidence, it is likely to include variation in behavioural risk factors such as smoking and physical activity, and also health care. The 
novel finding that the largest socioeconomic differences are among those who have had a prior CVD event and are therefore likely to be in contact with the health care system - reinforces the opportunity for, and importance of, optimal treatment and secondary prevention.

CVD is a national health priority for the Australian Government. Reducing the socioeconomic variation in incidence of both primary and secondary events should be a target in itself, not only to reduce health inequalities, but as a mechanism for lowering the overall burden of CVD morbidity and mortality in Australia.

\section{Additional files}

Additional file 1: Table S1. Comparison of models for major cardiovascular disease (CVD) events rates by level of education, in those with and without prior CVD. (PDF $185 \mathrm{~kb}$ )

Additional file 2: Table S2. Crude rates of ischemic heart disease events and adjusted hazard ratios (HR), by education, in those with and without prior CVD. (PDF $180 \mathrm{~kb}$ )

Additional file 3: Figure S1. Age-adjusted rates of major cardiovascular disease (CVD) events by household income and area-level disadvantage, in those with and without prior CVD. (PDF $228 \mathrm{~kb}$ )

Additional file 4: Table S3. Crude rates of major cardiovascular disease (CVD) events and adjusted hazard ratios (HR) by household income and area-level disadvantage, in those with and without prior CVD. (PDF 211 kb)

\section{Abbreviations}

ACHI: Australian classification of health interventions; APDC: Admitted patient data collection; Cl: Confidence intervals; CVD: Cardiovascular disease; HR: Hazard ratios; ICD-10-AM: International statistical classification of diseases and related health problems, tenth revision, Australian modification; IRSA: Index of Relative Socio-economic Advantage; NSW: New South Wales; NZ: New Zealand; RD: Rate difference; RR: Rate ratio; SD: Standard deviation; SEP: Socioeconomic position; UK: United Kingdom

\section{Acknowledgements}

This research was conducted in partnership with the National Heart Foundation of Australia, NSW Agency for Clinical Innovation and Consumers Health Forum of Australia. The study used data collected through the 45 and Up Study (www.saxinstitute.org.au). The 45 and Up Study is managed by the Sax Institute in collaboration with major partner Cancer Council NSW; and partners: the National Heart Foundation of Australia (NSW Division); NSW Ministry of Health; NSW Government Family \& Community Services - Carers, Ageing and Disability Inclusion; and the Australian Red Cross Blood Service. We thank the many thousands of people participating in the 45 and Up Study. The Cause of Death Unit Record File was provided by the Australian Coordinating Registry for the Cause of Death Unit Record File on behalf of Australian Registries of Births, Deaths and Marriages, Australian Coroners and the National Coronial Information System.

\section{Funding}

The research was funded by a National Health and Medical Research Council (NHMRC) Partnership Grant (GNT1092674). Author EB is supported by the NHMRC (ref 1042717).

\section{Ethics approval and consent to participate}

Ethics approval for this project was obtained from the NSW Population and Health Services Research Ethics Committee (AU RED Study Reference HREC) 10/CIPHS/33; CI NSW Study Reference 2010/05/234) and the Australian National University Human Research Ethics Committee (Study Reference 2010/513). Participants provided signed consent to participate in the study and for linkage of their information to a range of health databases.

\section{Authors' contributions}

RK designed the study, interpreted the data and drafted the manuscript KS performed the statistical analysis and reviewed the manuscript. BC and DW participated in drafting and reviewing the manuscript. GJ, JA and EB participated in study design and interpretation of the data, and revised the manuscript critically for important intellectual content. All authors read and approved the final manuscript.

\section{Competing interests}

The authors declare that they have no competing interest.

\section{Availability of data and materials}

Access to the Sax Institute's 45 and Up Study data is available to any bona fide researcher who has a scientifically sound and feasible research proposal; has ethics approval for the proposal and data custodian approval for access to linked data, if required for the project; and can meet 45 and Up Study licence and SURE (Secure Unified Research Environment) user charges. See https://www.saxinstitute.org.au/our-work/45-up-study/for-researchers.

\section{Author details}

${ }^{1}$ National Centre for Epidemiology and Population Health, Research School of Population Health, Australian National University, Canberra, ACT, Australia. ${ }^{2}$ National Drug and Alcohol Research Centre, UNSW Australia, Sydney, NSW, Australia. ${ }^{3}$ Centre for Clinical Epidemiology and Biostatistics, School of Medicine and Public Health, The University of Newcastle and Hunter Medical Research Institute, Newcastle, NSW, Australia. ${ }^{4}$ The Sax Institute, Sydney, NSW, Australia.

Received: 26 August 2016 Accepted: 2 November 2016 Published online: 21 November 2016

\section{References}

1. Lozano R, Naghavi M, Foreman K, Lim S, Shibuya K, Aboyans V, Abraham J, Adair T, Aggarwal R, Ahn SY, et al. Global and regional mortality from 235 causes of death for 20 age groups in 1990 and 2010: a systematic analysis for the Global Burden of Disease Study 2010. Lancet. 2012;380:2095-128.

2. Murray CJ, Vos T, Lozano R, Naghavi M, Flaxman AD, Michaud C, Ezzati M, Shibuya K, Salomon JA, Abdalla S, et al. Disability-adjusted life years (DALYS) for 291 diseases and injuries in 21 regions, 1990-2010: a systematic analysis for the Global Burden of Disease Study 2010. Lancet. 2012;380:2197-223.

3. Austalian Institute of Health and Welfare: Deaths from cardiovascular disease. [http://www.aihw.gov.au/cardiovascular-disease/deaths/] (2016). Accessed April 2016.

4. Australian Bureau of Statistics. Causes of death Australia, 2014. ABS cat. no. 3303.0. vol. Cat no.: 3303.0. Canberra: ABS; 2016.

5. Australian Institute of Health and Welfare. Health-care expenditure on cardiovascular diseases 2008-09. Cat. no. CVD 65. Canberra: AlHW; 2014.

6. Banks E, Crouch SR, Korda RJ, Stavreski B, Page K, Thurber KA, Grenfell R. Absolute risk of cardiovascular disease events, and blood pressure- and lipid-lowering therapy in Australia. Med J Aust. 2016;204:320.

7. Australian Institute of Health and Welfare. Cardiovascular disease: Australian facts 2011. Cardiovascular disease series. Cat. no. CVD 53. Canberra: AlHW; 2011.

8. Thrift AG, Dewey HM, Sturm JW, Paul SL, Gilligan AK, Srikanth VK, Macdonell RA, McNeil JJ, Macleod MR, Donnan GA. Greater incidence of both fatal and nonfatal strokes in disadvantaged areas: the Northeast Melbourne Stroke Incidence Study. Stroke. 2006;37:877-82.

9. AlHW, Moon L, Waters AM. Socioeconomic inequalities in cardiovascular disease in Australia: current picture and trends since the 1990s. Bulletin no. 37. AIHW cat. no. AUS 74. Canberra: Australian Institute of Health and Welfare; 2006

10. Page A, Lane A, Taylor R, Dobson A. Trends in socioeconomic inequalities in mortality from ischaemic heart disease and stroke in Australia, 1979-2006. Eur J Prev Cardiol. 2012;19:1281-9.

11. Honjo K, Tsutsumi A, Kayaba K. Socioeconomic indicators and cardiovascular disease incidence among japanese community residents: The jichi medical school cohort study. Int J Behav Med. 2010;17:58-66.

12. Chaix B, Rosvall M, Merlo J. Neighborhood socioeconomic deprivation and residential instability: Effects on incidence of ischemic heart disease and survival after myocardial infarction. Epidemiology. 2007;18:104-11.

13. Engstrom G, Hedblad B, Rosvall M, Janzon L, Lindgarde F. Occupation, marital status, and low-grade inflammation: mutual confounding or 
independent cardiovascular risk factors? Arterioscler Thromb Vasc Biol. 2006; 26:643-8.

14. Forssas EH, Keskimaki IT, Reunanen AR, Koskinen SV. Coronary heart disease among diabetic and nondiabetic people - socioeconomic differences in incidence, prognosis and mortality. J Diabetes Complications. 2008;22:10-7.

15. Igland J, Vollset SE, Nygard OK, Sulo G, Ebbing M, Tell GS. Educational inequalities in acute myocardial infarction incidence in Norway: a nationwide cohort study. PLoS ONE. 2014;9(9):e106898.

16. Koopman C, Van Oeffelen AA, Bots ML, Engelfriet PM, Verschuren WM, Van Rossem L, Van Dis I, Capewell S, Vaartjes I. Neighbourhood socioeconomic inequalities in incidence of acute myocardial infarction: A cohort study quantifying age- and gender-specific differences in relative and absolute terms. BMC Public Health. 2012;12:617.

17. Kuper H, Adami H-O, Theorell T, Weiderpass E. The Socioeconomic Gradient in the Incidence of Stroke: A Prospective Study in Middle-Aged Women in Sweden. Stroke. 2007;38:27-33.

18. Malki N, Koupil I, Eloranta S, Weibull CE, Tiikkaja S, Ingelsson E, Sparén P. Temporal trends in incidence of myocardial infarction and ischemic stroke by socioeconomic position in Sweden 1987-2010. PLoS ONE. 2014;9(8):e105279.

19. Méjean C, Droomers M, Van Der Schouw YT, Sluijs I, Czernichow S, Grobbee DE, Bueno-De-Mesquita HB, Beulens JWJ. The contribution of diet and lifestyle to socioeconomic inequalities in cardiovascular morbidity and mortality. Int J Cardiol. 2013;168:5190-5.

20. Silventoinen K, Pankow J, Jousilahti P, Hu G, Toumilehto J. Educational inequalities in the metabolic syndrome and coronary heart disease among middle-aged men and women. Int J Epidemiol. 2005;34:327-34.

21. Marmot MG, Shipley MJ, Hemingway H, Head J, Brunner EJ. Biological and behavioural explanations of social inequalities in coronary heart disease: The Whitehall II study. Diabetologia. 2008;51:1980-8.

22. Emberson JR, Whincup PH, Morris RW, Walker M. Social class differences in coronary heart disease in middle-aged British men: implications for prevention. Int J Epidemiol. 2004;33:289-96.

23. Avendano M, Glymour MM. Stroke Disparities in Older Americans: Is Wealth a More Powerful Indicator of Risk Than Income and Education? Stroke. 2008;39:1533-40.

24. Loucks EB, Lynch JW, Pilote L, Fuhrer R, Almeida ND, Richard H, Agha G, Murabito JM, Benjamin EJ. Life-course socioeconomic position and incidence of coronary heart disease: The Framingham Offspring Study. Am J Epidemiol. 2009;169:829-36.

25. Qureshi Al, Suri MF, Saad M, Hopkins LN. Educational attainment and risk of stroke and myocardial infarction. Med Sci Monit. 2003;9:CR466-473.

26. Veronesi G, Ferrario MM, Chambless LE, Sega R, Mancia G, Corrao G, Fornari C, Cesana G. Gender differences in the association between education and the incidence of cardiovascular events in Northern Italy. Eur J Pub Health. 2011;21:762-7.

27. Woodward M, Oliphant J, Lowe G, Tunstall-Pedoe H. Contribution of contemporaneous risk factors to social inequality in coronary heart disease and all causes mortality. Prev Med. 2003;36:561-8.

28. Yarnell J, Yu S, McCrum E, Arveiler D, Hass B, Dallongeville J, Montaye M, Amouyel P, Ferrieres J, Ruidavets JB, et al. Education, socioeconomic and lifestyle factors, and risk of coronary heart disease: the PRIME Study. Int J Epidemiol. 2005;34:268-75.

29. Gillum RF, Mussolino ME. Education, poverty, and stroke incidence in whites and blacks: the NHANES I Epidemiologic Follow-up Study. J Clin Epidemiol. 2003:56:188-95.

30. Woodward M, Peters SAE, Batty GD, Ueshima H, Woo J, Giles GG, Barzi F, Ho SC, Huxley RR, Arima $\mathrm{H}$, et al. Socioeconomic status in relation to cardiovascular disease and causespecific mortality: A comparison of Asian and Australasian populations in a pooled analysis. BMJ Open. 2015;5(3):e006408.

31. Marshall IJ, Wang Y, Crichton S, McKevitt C, Rudd AG, Wolfe CDA. The effects of socioeconomic status on stroke risk and outcomes. Lancet Neurol. 2015;14:1206-18

32. Mather T, Banks E, Joshy G, Bauman A, Phongsavan P, Korda RJ. Variation in health inequalities according to measures of socioeconomic status and age. Aust N Z J Public Health. 2014;38:436-40.

33. Banks E, Redman S, Jorm L, Armstrong B, Bauman A, Beard J, Beral V, Byles J, Corbett S, Cumming R, et al. Cohort profile: the 45 and up study. Int J Epidemiol. 2008;37:941-7.

34. The Sax Institute: The 45 and Up Study - Questionnaires [https:/www. saxinstitute.org.au/our-work/45-up-study/questionnaires/] (2016). Accessed April 2016
35. Joshy G, Korda RJ, Abhayaratna WP, Soga K, Banks E. Categorising major cardiovascular disease hospitalisations from routinely collected data. Public Health Res Pract. 2015;25:e2531532.

36. Australian Bureau of Statistics. 2039.0 - Information paper: an introduction to socio-economic indexes for areas (SEIFA), 2006. Canberra: ABS; 2008.

37. Fay M, Feuer E. Confidence intervals for directly adjusted rates: a method based on the gamma distribution. Stat Med. 1997;16:791-801.

38. Manrique-Garcia E, Sidorchuk A, Hallqvist J, Moradi T. Socioeconomic position and incidence of acute myocardial infarction: a meta-analysis. J Epidemiol Community Health. 2011;65:301-9.

39. Lammintausta A, Immonen-Räihä P, Airaksinen JKE, Torppa J, Harald K Ketonen M, Lehto S, Koukkunen H, Kesäniemi AY, Kärjä-Koskenkari P, Salomaa V. Socioeconomic Inequalities in the Morbidity and Mortality of Acute Coronary Events in Finland: 1988 to 2002. Ann Epidemiol. 2012;22:87-93.

40. Li C, Hedblad B, Rosvall M, Buchwald F, Khan FA, Engstrom G. Stroke incidence, recurrence, and case-fatality in relation to socioeconomic position: a population-based study of middle-aged Swedish men and women. Stroke. 2008;39:2191-6.

41. Ramsay SE, Morris RW, Whincup PH, Papacosta O, Rumley A, Lennon L, Lowe G, Wannamethee SG. Socioeconomic inequalities in coronary heart disease risk in older age: Contribution of established and novel coronary risk factors. J Thromb Haemost. 2009:7:1779-86.

42. Hart CL, Hole DJ, Smith GD. The contribution of risk factors to stroke differentials, by socioeconomic position in adulthood: the Renfrew/Paisley Study. Am J Public Health. 2000;90:1788-91.

43. Pujades-Rodriguez M, Timmis A, Stogiannis D, Rapsomaniki E, Denaxas S, Shah A, Feder G, Kivimaki M, Hemingway H. Socioeconomic deprivation and the incidence of 12 cardiovascular diseases in 1.9 million women and men: implications for risk prediction and prevention. PLoS ONE. 2014;9:e104671.

44. Jackson CA, Jones M, Mishra GD. Educational and homeownership inequalities in stroke incidence: A population-based longitudinal study of mid-aged women. Eur J Pub Health. 2014;24:231-6.

45. Heeley EL, Wei JW, Carter K, Islam MS, Thrift AG, Hankey GJ, Cass A, Anderson CS. Socioeconomic disparities in stroke rates and outcome: pooled analysis of stroke incidence studies in Australia and New Zealand. Med J Aust. 2011;195:10-4.

46. Cesaroni G, Agabiti N, Forastiere F, Perucci CA. Socioeconomic differences in stroke incidence and prognosis under a universal healthcare system. Stroke. 2009:40:2812-9.

47. Mohan KM, Crichton SL, Grieve AP, Rudd AG, Wolfe CD, Heuschmann PU. Frequency and predictors for the risk of stroke recurrence up to 10 years after stroke: the South London Stroke Register. J Neurol Neurosurg Psychiatry. 2009;80:1012-8.

48. Vathesatogkit P, Batty GD, Woodward M. Socioeconomic disadvantage and disease-specific mortality in Asia: Systematic review with meta-analysis of population-based cohort studies. J Epidemiol Community Health. 2014;68:375-83.

49. Rothman K, Greenland S. Precision and validity in epidemiologic studies. In: Rothman KJ, Greenland S, editors. Modern epidemiology. 2nd ed. Philadelphia PA: Lippincott-Raven Publishers; 1998. p. 115-34.

50. Mealing NM, Banks E, Jorm LR, Steel DG, Clements MS, Rogers KD. Investigation of relative risk estimates from studies of the same population with contrasting response rates and designs. BMC Med Res Methodol. 2010;10:26.

\section{Submit your next manuscript to BioMed Central and we will help you at every step:}

- We accept pre-submission inquiries

- Our selector tool helps you to find the most relevant journal

- We provide round the clock customer support

- Convenient online submission

- Thorough peer review

- Inclusion in PubMed and all major indexing services

- Maximum visibility for your research

Submit your manuscript at www.biomedcentral.com/submit
Biomed Central 